\title{
PENGARUH KEPEMIMPINAN KEPALA SEKOLAH, BUDAYA DAN KOMITE SEKOLAH TERHADAP KEPUASAN PELAYANAN
}

\author{
Teddy Manueke ${ }^{1}$, Deitje A. Katuuk ${ }^{2}$, Viktory N. J. Rotty ${ }^{3}$, Jeffry S. J. Lengkong ${ }^{4}$ \\ ${ }^{1}$ Universitas Negeri Manado, Manado Indonesia \\ e-mail: teddy.manueke@yahoo.co.id \\ ${ }^{2}$ Universitas Negeri Manado, Manado Indonesia \\ e-mail: Deitjekatuuk@unima.ac.id \\ ${ }^{3}$ Universitas Negeri Manado, Manado Indonesia \\ e-mail: Viktoryrotty@unima.ac.id \\ ${ }^{4}$ Universitas Negeri Manado, Manado Indonesia \\ e-mail: Jeffrylengkong@unima.ac.id
}

DOI: 10.35719/leaderia.v2i1.60

\begin{abstract}
This study aims to measure two types of variables, independent variable consisting of the principal's leadership, school culture and school committees and the dependent variable, service satisfaction. The subjects of this study were teachers of SMK Negeri in Bitung totaling 241 with a sample of 71 people. The method used is a descriptive analytical survey method and uses correlational analysis. The analysis technique used is Pearson Product Moment Correlational Analysis. The results showed that there was a significant influence of principal's leadership on service satisfaction of State Vocational Schools in Bitung City by 44.9\%. There is an influence of school culture on service satisfaction of State Vocational Schools in Bitung City by 49\%. There is an influence of school committees on service satisfaction of State Vocational Schools in Bitung City by 33.7\%. There is an effect of principal leadership and school culture together on service satisfaction of State Vocational Schools in Bitung City by $46.3 \%$. There is an influence of the leadership of the principal and the school committee together on the service satisfaction of State Vocational Schools in Bitung City by $46.5 \%$. There is an influence of school culture and school committee together on service satisfaction of State Vocational Schools in Bitung City 45.4\%. There is a joint influence of the principal's leadership, school culture and school committee on service satisfaction of State Vocational Schools in Bitung City by $47.9 \%$.
\end{abstract}

Keywords: principal's leadership, school culture, school committee, service satisfaction

\section{ABSTRAK}

Penelitian ini bertujuan mengukur dua jenis variabel, yaitu: variabel bebas yang terdiri atas kepemimpinan kepala sekolah, budaya sekolah dan komite sekolah serta variabel terikat yaitu variabel kepuasan pelayanan. Subjek penelitian ini adalah guru-guru SMK Negeri di Bitung yang berjumlah 241 dengan penarikan sampel sebanyak 71 orang. Metode yang digunakan adalah metode survey yang bersifat 
deskriptif analitis dan menggunakan analisis korelasional. Teknik analisa yang digunakan adalah Analisis Korelasional Pearson Product Moment. Hasil penelitian menunjukkan terdapat pengaruh yang signifikan kepemimpinan kepala sekolah terhadap kepuasan pelayanan SMK Negeri di Kota Bitung sebesar 44,9\%. Terdapat pengaruh budaya sekolah terhadap kepuasan pelayanan SMK Negeri di Kota Bitung sebesar 49\%. Terdapat pengaruh komite sekolah terhadap kepuasan pelayanan SMK Negeri di Kota Bitung sebesar 33,7\%. Terdapat pengaruh kepemimpinan kepala sekolah dan budaya sekolah secara bersama-sama terhadap kepuasan pelayanan SMK Negeri di Kota Bitung sebesar 46,3\%. Terdapat pengaruh kepemimpinan kepala sekolah dan komite sekolah secara bersama-sama terhadap kepuasan pelayanan SMK Negeri di Kota Bitung sebesar 46,5\%. Terdapat pengaruh budaya sekolah dan komite sekolah secara bersama-sama terhadap kepuasan pelayanan SMK Negeri di Kota Bitung 45,4\%. Terdapat pengaruh kepemimpinan kepala sekolah, budaya sekolah dan komite sekolah secara bersama-sama terhadap kepuasan pelayanan SMK Negeri di Kota Bitung sebesar 47,9\%.

Kata Kunci: Kepala Sekolah, Kepemimpinan, Budaya, Komite, Kepuasan Pelayanan

\section{PENDAHULUAN}

Sekolah sebagai suatu lembaga pendidikan sekarang ini diperhadapkan kepada berbagai permasalahan termasuk di dalamnya masalah yang berkaitan dengan tugas kepala sekolah yang begitu luas dan membutuhkan perhatian khusus seiring dengan perubahanperubahan dan perbaikan serta perkembangan sistem pendidikan untuk selalu memperbaiki dan mengembangkan diri selaku tenaga kependidikan yang mempunyai kemampuan khusus sebagai sumber kepuasan pelayanan serta kepala sekolah sebagai manajer sekolah. Wahjosumidjo (2003:83) mendefinisikan kepala sekolah sebagai seorang tenaga fungsional guru yang diberi tugas untuk memimpin suatu sekolah dimana diselenggarakan proses belajar mengajar, atau tempat dimana terjadi interaksi antara guru yang memberi pelajaran dan murid yang menerima pelajaran, selanjutnya Paul Hersey dkk (Wahjosumidjo, 2003:99) menyatakan bahawa dalam rangka pelaksanaan tugas-tugas manajerial paling tidak diperlukan tiga macam bidang keterampilan yaitu: technical, human dan conceptual. Ketiga keterampilan manajerial tersebut berbeda-neda sesuai dengan tingkat kedudukan manajer dalam organisasi. Upaya meningkatkan kualitas pendidikan yang dimaksud harus ditunjang oleh berbagai komponen, salah satunya adalah komponen guru yang mempunyai peran penting dan merupakan kunci pokok bagi keberhasilan pendidikan, untuk itu kemampuan profesional guru perlu ditingkatkan dan dikembangkan dengan berbagai upaya, antara lain melalui pendidikan, pelatihan dan pembinaan teknis yang dilakukan secara berkesinambungan di sekolah dan lainnya. Menurut Salim , Azwardi, Mutiara Ritonga, Rica Widiastuty “ Developing the quality of 
education in a school is inseparable from the role and responsibility of the principal. “(2021: 25-32)

Arikunto (2009: 3) Pendidikan merupakan bagian penting dari proses pembangunan nasional yang memiliki andil besar untuk menentukan masa depan suatu bangsa, selain itu pendidikan merupakan investasi dalam pengembangan sumber daya manusia, dimana bidang pendidikan akan berpengaruh terhadap pola pikir dan peningkatan kecakapan, kinerja dan kemampuan diyakini sebagai faktor penting pendukung upaya manusia dalam mengarungi kehidupan. Untuk menghasilkan Pendidikan yang bermutu salah satu aspek yang harus diperhatikan adalah sumber daya manusianya, setiap sumber daya manusia yang ada dalam sebuah institusi pendidikan harus memiliki sifat profesionalitas yang tinggi dan harus kompeten dalam bidangnya. Lembaga pendidikan yang biasa disebut sekolah merupakan lembaga formal yang memberikan pelayanan jasa dan memberikan pendidikan yang bermutu bagi para peserta didiknya. Dengan begitu sekolah dituntut untuk selalu meningkatkan mutu seluruh komponen yang ada di dalam sekolah tersebut.

Untuk mencapai keberhasilan suatu pendidikan tersebut sangat ditentukan oleh profesionalisme seorang guru dan kepuasan pelayanan guru. Hal ini secara langsung maupun tidak langsung akan mempengaruhi produktivitas kerja, ketika guru merasa puas, maka kinerjanya akan semakin tinggi. Kepuasan pelayanan seorang guru merupakan sarana penting dalam manajemen sumber daya manusia. Kepuasan pelayanan guru yang rendah akan menyebabkan seorang guru menjadi malas bekerja, kemangkiran, banyak keluhan, rendahnya pestasi kerja, rendahnya kualitas pengajaran, indisipliner guru dan gejala negatif lainnya.

Kepala sekolah merupakan salah satu sumber daya manusia yang berperan sangat penting dalam mengatur dan mengendalikan seluruh sumber daya yang terkait di bidang satuan pendidikan khususnya di sekolah. Kepala sekolah merupakan sosok penting dalam sekolah karena kepala sekolah bertanggung jawab atas kemajuan dan mundurnya serta baik buruknya sebuah sekolah.

Kepemimpinan kepala sekolah dalam satuan pendidikan di sekolah merupakan motor penggerak bagi semua sumber daya sekolah yang diharapkan mampu untuk menggerakkan guru agar lebih efektif, membangun dan membina hubungan baik antar lingkungan sekolah supaya tercipta suasana yang kondusif, menggairahkan, produktif dan bersama-sama agar mampu melaksanakan perencanaan, pelaksanaan dan evaluasi terhadap berbagai jenis kebijakan dan perubahan yang telah dilakukan secara efektif dan efisien supaya semua diarahkan untuk menghasilkan produk atau lulusan yang berkualitas serta memiliki kompetensi yang unggul.

Peningkatan dan pengembangan kepuasan pelayanan guru tersebut meliputi berbagai aspek, antara lain: kemampuan guru dalam menguasai kurikulum, materi pengajaran, kemampuan menciptakan media pengajaran yang relevan, kemampuan dalam menggunakan metode dan sarana 
dalam proses belajar mengajar, melaksanakan evaluasi dan hasil belajar, disiplin dan komitmen guru terhadap tugas.

Keberadaan guru sebagai garis terdepan dalam proses pendidikan dan pengajaran selalu disoroti oleh berbagai pihak yang merasakan dampak dari hasil pendidikan dimana guru berperan. Mengatasi permasalahan yang dihadapi guru perlu adanya berbagai upaya oleh pemerintah dalam hal ini instansi terkait melalui kepala sekolah dengan memberikan bimbingan, arahan maupun pembinaan, sehingga dapat menumbuhkan dinamika dan kreativitas mengajar guru yang lebih profesional, karena pembinaan serta bimbingan itu akan membantu memperlancar proses belajar mengajar yang dikelolah secara kreatif oleh guru akan mampu membuat siswa menjadi kreatif dan produktif.

Upaya meningkatkan mutu Pendidikan atau dalam hal ini adalah kepuasan pelayanan guru di sekolah SMK Negeri di Kota Bitung menuntut kepala sekolah, komite sekolah yang diarahkan pada peningkatan efektivitas guru dalam mengembangkan dan menguasai metode pembelajaran. Pemahaman dan pengembangan keterampilan-keterampilan, metode mengajar guru, ternyata hal ini tidak lepas dari pengaruh kepemimpinan kepala sekolah dalam upaya meningkatkan kepuasan pelayanan kerja guru-guru dalam upaya untuk mencapai tujuan pendidikan yang dimaksud. Faktor yang menentukan untuk meningkatkan kepuasan pelayanan guru tersebut di atas sebetulnya bukan hanya kepemimpinan dan penalaran kepala sekolah, budaya sekolah juga sangat mempengaruhi dan komite sekolah dan masih banyak faktor yang mempengaruhinya. Dalam penelitian ini hanya difokuskan kepada faktor kepemimpinan kepala sekolah, budaya sekolah, dan komite sekolah terhadap kepuasan pelayanan. berdasarkan alasan di atas, maka di dalam penelitian ini, peneliti ingin mengetahui pengaruh kepemimpinan kepala sekolah, budaya sekolah, dan peran komite sekolah terhadap kepuasan pelayanan smk negeri di kota bitung. rumusan masalah:

a. Apakah terdapat pengaruh kepemimpinan kepala sekolah terhadap kepuasan pelayanan SMK Negeri di Kota Bitung?

b. Apakah terdapat pengaruh budaya sekolah terhadap kepuasan pelayanan SMK Negeri di Kota Bitung?

c. Apakah terdapat pengaruh komite sekolah terhadap kepuasan pelayanan SMK Negeri di Kota Bitung?

d. Apakah terdapat pengaruh kepemimpinan dan budaya sekolah secara bersama-sama terdahap kepuasan pelayanan SMK Negeri di Kota Bitung?

e. Apa terdapat pengeruh kepemimpinan kepala sekolah dan komite sekolah secara bersama-sama terhadap kepuasan pelayanan SMK Negeri di Kota Bitung?

f. Apakah terdapat pengaruh budaya sekolah dan komite sekolah secara bersama-sama terhadap kepuasan pelayanan SMK Negeri di Kota Bitung? 
g. Apakah terdapat pengaruh secara bersama-sama antara kepemimpinan kepala sekolah, budaya sekolah, komite sekolah secara bersama-sama terhadap kepuasan pelayanan SMK Negeri di Kota Bitung?

Dengan demikian maka tujuan penelitian ini adalah untuk mengetahui pengaruh kepemimpinan kepala sekolah, budaya sekolah, dan peran komite sekolah terhadap kepuasan pelayanan SMK Negeri di Kota Bitung.

\section{METODE}

Dalam penelitian ini menggunakan pendekatan deskriptif kuantitatif, dengan menggunakan analisis regresi. Penelitian Deskriptif merupakan dasar dari semua penelitian. Penelitian Deskriptif dilakukan secara kuantitatif agar dapat dilakukan analisis statistik (Basuki, 2006:110). Metode yang digunakan dalam penelitian ini adalah "survey". Menurut Hasan, (2010:8) metode survei adalah cara penelitian yang dilakukan untuk memperoleh fakta-fakta dari gejala-gejala yang ada dan mencari keterangan-keterangan secara aktual, baik tentang situasi sosial, ekonomi atau politik dari suatu kelompok atau daerah.

Berdasarkan uraian tersebut, maka peneliti akan mencari fakta-fakta dan keteranganketerangan atau informasi mengenai pengaruh kepemimpinan kepala sekolah, budaya sekolah dan peran komite sekolah terhadap Kepuasan Pelayanan SMK Negeri di Kota Bitung dan mencari keterangan-keterangan secara aktual, baik tentang situasi sosial, ekonomi atau politik dari suatu kelompok atau daerah.

\section{Teknik Pengumpulan Data}

Penelitian ini akan mengukur dua jenis variabel, yaitu: (1) variabel bebas yang terdiri atas kepemimpinan kepala sekolah (X1), budaya sekolah (X2) dan komite sekolah (X3) serta (2) variabel terikat yaitu variabel kepuasan pelayanan (Y).

Dalam penelitian ini digunakan teknik angket (Kuesioner) yang disusun dengan sejumlah pertanyaan dengan menggunakan skala likert. Teknik angket yang dilakukan dengan menggunakan empat koesioner yaitu:

1. Angket untuk mengukur kepemimpinan kepala sekolah

2. Angket untuk mengukur budaya sekolah

3. Angket untuk mengukur peran komite sekolah

4. Angket untuk mengukur kinerja guru

Kisi-kisi soal atau koesioner secara tertutup yang terdiri dari 5 alternatif jawaban yang menggunakan skala likert 1 sampai 5. Jawaban setiap item instrumen yang menggunakan skala likert mempunyai gradasi dari sangat positif sampai negatif dan untuk keperluan analisis kuantitatif, maka jawaban itu diberi skor:

$\mathrm{Sl}=$ Selalu diberi skor $\quad: 5$ 
$\begin{array}{ll}\mathrm{Sr}=\text { Sering diberi skor } & : 4 \\ \mathrm{Jr}=\text { Jarang diberi skor } & : 3 \\ \mathrm{SJ}=\text { Jarang Sekali diberi skor } & : 2 \\ \mathrm{TP}=\text { Tidak Pernah diberi skor } & : 1\end{array}$

\section{HASIL DAN PEMBAHASAN}

Hasil

Pengaruh Kepemimpinan Kepala Sekolah (X1) Terhadap Kepuasan Pelayanan (Y). Hasil pengujian hipotesis menunjukkan terdapat pengaruh positif dan signifikan variabel kepemimpinann kepala sekolah terhadap kepuasan pelayanan. Hubungan fungsional variabel kepemimpinan kepala sekolah terhadap kepuasan pelayanan dapat digambarkan dalam persamaan garis regresi .

Koefisien regresi yang bernilai positif menunjukkan bahwa pengaruh yang diberikan variabel kepemimpinan kepala sekolah bernilai positif. Variabel budaya sekolah naik sebesar $67,8 \%$ jika variabel kepemimpinan kepala sekolah ditingkatkan 100\%. Hal ini diperjelas dengan pengaruh yang kuat antara variabel kepemimpinan kepala sekolah dengan kepuasan pelayanan sebesar 0,670 .

Besarnya pengaruh yang diberikan oleh variabel kepemimpinan kepala sekolah terhadap peningkatan kepuasan pelayanan adalah sebesar 44,9\%. Pengaruh variabel kepemimpinan kepala sekolah terhadap kepuasan pelayanan adalah signifikan. Hal ini mengartikan bahwa variabel kepemimpinan kepala sekolah merupakan salah satu faktor yang mempengaruhi kepuasan pelayanan, sehingga patut diperhatikan untuk peningkatan kepuasan pelayanan.

Pengaruh Positif Budaya Sekolah (X2) Terhadap Kepuasan Pelayanan (Y). Hasil pengujian hipotesis menunjukkan terdapat pengaruh positif dan signifikan variabel budaya sekolah terhadap kepuasan pelayanan. Hubungan fungsional variabel budaya sekolah terhadap kepuasan pelayanan dapat digambarkan dalam persamaan garis regresi .

Koefisien regresi yang bernilai positif menunjukkan bahwa pengaruh yang diberikan variabel budaya sekolah bernilai positif. Variabel budaya sekolah naik sebesar 72,5\% jika variabel budaya sekolah ditingkatkan $100 \%$. Hal ini diperjelas dengan pengaruh yang kuat antara variabel budaya sekolah dengan kepuasan pelayanan sebesar 0,629.

Besarnya pengaruh yang diberikan oleh variabel budaya sekolah terhadap peningkatan kepuasan pelayanan adalah sebesar 49,5\%. Pengaruh variabel budaya sekolah terhadap kepuasan pelayanan adalah signifikan. Hal ini mengartikan bahwa variabel budaya sekolah merupakan salah satu faktor yang mempengaruhi kepuasan pelayanan, sehingga patut diperhatikan untuk peningkatan kepuasan pelayanan.

Pengaruh Komite Sekolah (X3) Terhadap Kepuasan Pelayanan (Y). Hasil pengujian hipotesis menunjukkan terdapat pengaruh positif dan signifikan variabel komite sekolah terhadap 
kepuasan pelayanan. Hubungan fungsional variabel komite sekolah terhadap kepuasan pelayanan dapat digambarkan dalam persamaan garis regresi .

Koefisien regresi yang bernilai positif menunjukkan bahwa pengaruh yang diberikan variabel budaya bernilai positif. Variabel komite sekolah naik sebesar 58\% jika variabel komite sekolah ditingkatkan $100 \%$. Hal ini diperjelas dengan pengaruh yang kuat antara variabel komite sekolah dengan kepuasan pelayanan sebesar 0,580.

Besarnya pengaruh yang diberikan oleh variabel komite sekolah terhadap peningkatan kepuasan pelayanan adalah sebesar 33,7\%. Pengaruh variabel komite sekolah terhadap kepuasan pelayanan adalah signifikan. Hal ini mengartikan bahwa variabel komite sekolah merupakan salah satu faktor yang mempengaruhi kepuasan pelayanan, sehingga patut diperhatikan untuk peningkatan kepuasan pelayanan.

Pengruh Kepemimpinan Kepala Sekolah (X1) dan Budaya Sekolah (X2) Secara BersamaSama Terhadap Kepuasan Pelayanan (Y). Hasil pengujian hipotesis menunjukkan terdapat pengaruh positif dan signifikan variabel kepemimpinan kepala sekolah dan variabel budaya sekolah secara bersama-sama terhadap kepuasan pelayanan. Hubungan fungsional variabel kepemimpinan kepala sekolah dan budaya sekolah terhadap kepuasan pelayanan dapat digambarkan dalam persamaan garis regresi .

Koefisien regresi yang bernilai positif menunjukkan bahwa pengaruh yang diberikan variabel kepemimpinan kepala sekolah dan budaya sekolah memberikan pengaruh yang positif. Hal ini diperjelas dengan pengaruh yang kuat antara variabel kepemimpinan kepala sekolah dan budaya sekolah terhadap kepuasan pelayanan sebesar 0,681.

Besarnya pengaruh yang diberikan oleh variabel kepemimpinan kepala sekolah dan budaya sekolah terhadap peningkatan kepuasan pelayanan adalah sebesar 46,3\%. Pengaruh variabel kepemimpinan kepala sekolah dan budaya sekolah terhadap kepuasan pelayanan adalah signifikan. Hal ini mengartikan bahwa variabel kepemimpinan kepala sekolah dan variabel budaya sekolah merupakan faktor-faktor yang patut diperhitungkan untuk meningkatkan kepuasan pelayanan.

Pengaruh Kepemimpinan Kepala Sekolah (X1) dan Komite Sekolah (X3) Secara BersamaSama Terhadap Kepuasan Pelayanan (Y). Hasil pengujian hipotesis menunjukkan terdapat pengaruh positif dan signifikan variabel kepemimpinan kepala sekolah dan variabel komite sekolah secara bersama-sama terhadap kepuasan pelayanan. Hubungan fungsional variabel kepemimpinan kepala sekolah dan variabel komite sekolah terhadap kepuasan pelayanan dapat digambarkan dalam persamaan garis regresi .

Koefisien regresi yang bernilai positif menunjukkan bahwa pengaruh yang diberikan variabel kepemimpinan kepala sekolah dan variable komite sekolah memberikan pengaruh yang positif. Hal ini diperjelas dengan pengaruh yang kuat antara variabel kepemimpinan kepala sekolah dan komite sekolah terhadap kepuasan pelayanan sebesar 0,682. 
Besarnya pengaruh yang diberikan oleh variabel kepemimpinan kepala sekolah dan komite sekolah terhadap peningkatan kepuasan pelayanan adalah sebesar 46,5\%. Pengaruh variabel kepemimpinan kepala sekolah dan variabel komite sekolah terhadap kepuasan pelayanan adalah signifikan. Hal ini mengartikan bahwa variabel kepemimpinan kepala sekolah dan variabel komite sekolah merupakan faktor-faktor yang patut diperhitungkan untuk meningkatkan kepuasan pelayanan.

\section{Pembahasan}

Hasil pengujian hipotesis menunjukkan terdapat pengaruh positif dan signifikan variabel budaya sekolah dan variabel komite sekolah secara bersama-sama terhadap kepuasan pelayanan. Hubungan fungsional variabel budaya sekolah dan komite sekolah terhadap kepuasan pelayanan dapat digambarkan dalam persamaan garis regresi .

Koefisien regresi yang bernilai positif menunjukkan bahwa pengaruh yang diberikan variabel budaya sekolah dan variabel komite sekolah memberikan pengaruh yang positif. Hal ini diperjelas dengan pengaruh yang kuat antara variabel budaya sekolah dan variabel komite sekolah terhadap kepuasan pelayanan sebesar 0,673.

Besarnya pengaruh yang diberikan oleh variabel budaya sekolah dan variabel komite sekolah terhadap peningkatan kepuasan pelayanan adalah sebesar $45,4 \%$.

Pengaruh variabel budaya sekolah dan variabel komite sekolah terhadap kepuasan pelayanan adalah signifikan. Hal ini mengartikan bahwa variabel budaya sekolah dan variabel komite sekolah merupakan faktor-faktor yang patut diperhitungkan untuk meningkatkan kepuasan pelayanan.

Pengaruh Kepemimpinan Kepala Sekolah (X1), Budaya Sekolah (X2) dan Komite Sekolah (X3) Secara Bersama-Sama Terhadap Kepuasan Pelayanan

Hasil pengujian hipotesis menunjukkan terdapat pengaruh positif dan signifikan variabel kepemimpinan kepala sekolah, variabel budaya sekolah dan variabel komite sekolah secara bersama-sama terhadap kepuasan pelayanan. Hubungan fungsional variabel kepemimpinan kepala sekolah, budaya sekolah dan komite sekolah terhadap kepuasan pelayanan dapat digambarkan dalam persamaan garis regresi .

Koefisien regresi yang bernilai positif menunjukkan bahwa pengaruh yang diberikan variabel kepemimpinan kepala sekolah, variabel budaya sekolah dan variabel komite sekolah memberikan pengaruh yang positif. Hal ini diperjelas dengan pengaruh yang kuat antara variabel kepemimpinan kepala sekolah, variabel budaya sekolah dan variabel komite sekolah terhadap kepuasan pelayanan sebesar 0,692.

\section{KESIMPULAN DAN SARAN}

Terhadap kepuasan pelayanan. Jadi semakin baik kepemimpinan kepala sekolah maka sepuasan pelayanan semakin baik. 
Terdapat pengaruh yang positif dan signifikan budaya sekolah terhadap kepuasan pelayanan. Jadi semakin kondusif budaya sekolah yang ada disekolah akan meningkatkan kepuasan pelayanan.

Terdapat pengaruh yang positif dan signifikan komite sekolah terhadap kepuasan pelayanan. Jadi semakin baik program komite sekolah akan meningkatkan kepuasan pelayanan.

Terdapat pengaruh yang positif dan signifikan kepemimpinan kepala sekolah dan budaya sekolah secara bersama-sama terhadap kepuasan pelayanan. Jadi kepemimpinan kepala sekolah yang baik dan didukung dengan budaya sekolah yang kondusif akan meningkatkan kepuasan pelayanan.

Terdapat pengaruh yang positif dan signifikan kepemimpinan kepala sekolah dan komite sekolah secara bersama-sama terhadap kepuasan pelayanan. Jadi kepemimpinan kepala sekolah yang baik dan didukung dengan komite sekolah akan meningkatkan kepuasan pelayanan.

Terdapat pengaruh yang positif dan signifikan budaya sekolah dan komite sekolah secara bersama-sama terhadap kepuasan pelayanan. Jadi budaya sekolah yang kondusif dan di dukung dengan program komite sekolah yang berjalan dengan baik akan meningkatkan kepuasan pelayanan.

Terdapat pengaruh yang positif dan signifikan kepemimpinan kepala sekolah, budaya sekolah dan komite sekolah secara bersama-sama terhadap kepuasan pelayanan. Jadi kepemimpinan kepala sekolah yang baik dan budaya sekolah yang kondusif serta didukung dengan program komite sekolah yang berjalan dengan baik akan meningkatkan kepuasan pelayanan. Terdapat pengaruh yang positif dan signifikan kepemimpinan kepala sekolah.

\section{DAFTAR PUSTAKA}

Achmad, Sanusi (2009). Kepemimpinan Sekarang dan Masa Depan Membentuk Budaya Organisasi yang Efektif. Bandung: Prospect.

Arikunto, Suharsimi (2009). Evaluasi Program Pendidikan Pedoman Teoretis Praktisbagi Mahasiswa dan Praktisi Pendidik. Jakarta : PT Bumi Aksara.

Basuki, Sulistyo (2006). Metode Penelitian. Jakarta: Wedatama Widya Sastra dan Fakultas Ilmu Pengetahuan Budaya Universitas Indonesia.

Depdiknas (2007). Peraturan Menteri Pendidikan Nasional Republik Indonesia Nomor 12 Tahun 2007 Tentang Standar Pengawasan Sekolah/Madrasah. Jakarta: Depdikbud.

Hasan, Iqbal (2010). Analisis Data Penelitian Dengan Statistik. Jakarta: Bumi Aksara.

Undang-Undang Republik Indonesia Nomor 20 Tahun 2003 Sistem Pendidikan Nasional. 8 Juli 2003. Lembaga Negara Republik Indonesia Tahun 2003 Nomor 78. Jakarta

Wahjosumidjo (2002). Kepemimpinan Kepala Sekolah Tinjauan Teoritik dan Permasalahannya. Jakarta: Rajawali Pers. 
Zamroni (2003). Manajemen Berbasis Sekolah: Piranti Reformasi System Pendidikan.

Zuchdi, Darmiyati (2011). Pendidikan Karekter Perspektif Teori dan Praktik. Yogyakarta: UNY Press.

Kotler Philip, Kevin Lane (2009). Manajemen Pemasaran. Edisi Ke 13 jilid 1 dan 2, Jakarta, Erlangga.

Dirgantari, P. Dewi (2012). Pengaruh Kualitas Layanan Jasa Pendidikan Terhadap Kepuasan Mahasiswa Serta Dampaknya Terhadap Upaya Peningkatan Citra Perguruan Tinggi Negeri Menuju World Class University. Bandung: Jurnal Ilmu Manajemen dan Bisnis Vol 3, No 2:1-25. 